\title{
2p13.2 microdeletion syndrome
}

INSERM

\section{Source}

INSERM. (1999). Orphanet: an online rare disease and orphan drug data base. 2p13.2 microdeletion syndrome. ORPHA:363680

2 p13.2 microdeletion syndrome is a rare partial autosomal monosomy characterized by global development delay, intellectual disability, behavioral abnormalities (hyperactivity, attention deficit and autistic behaviors), brachycephaly and variable facial dysmorphism. Other associated features may include vertebral fusions, mild contractures of knees and elbows, and feeding difficulties during infancy. 